\title{
Archival Work as Qualitative Sociology
}

\section{Claudio E. Benzecry ${ }^{1} \cdot$ Andrew Deener ${ }^{2} \cdot$ Armando Lara-Millán $^{3}$}

C Springer Science+Business Media, LLC, part of Springer Nature 2020

Everything would be in its blind volumes. Everything: the detailed history of the future, Aeschylus' The Egyptians, the exact number of times that the waters of the Ganges have reflected the flight of a falcon, the secret and true nature of Rome, the encyclopedia Novalis would have constructed, my dreams and half-dreams at dawn on August 14, 1934, the proof of Pierre Fermat's theorem, the unwritten chapters of Edwin Drood, those same chapters translated into the language spoken by the Garamantes, the paradoxes Berkeley invented concerning Time but didn't publish, Urizen's books of iron, the premature epiphanies of Stephen Dedalus, which would be meaningless before a cycle of a thousand years, the Gnostic Gospel of Basilides, the song the sirens sang, the complete catalog of the Library, the proof of the inaccuracy of that catalog. Everything: but for every sensible line or accurate fact there would be millions of meaningless cacophonies, verbal farragoes, and babblings. Everything: but all the generations of mankind could pass before the dizzying shelves-shelves that obliterate the day and on which chaos lies-ever reward them with a tolerable page.

Jorge Luis Borges. "La biblioteca total" (The Total Library).

In the Total Library, we see the duality of the archive at play. It is a project (a paranoid one) of total knowledge, as well as the control of knowledge that comes with it; it raises the possibility

Andrew Deener

andrew.deener@uconn.edu

Claudio E. Benzecry

claudio.benzecry@northwestern.edu

Armando Lara-Millán

armando@berkeley.edu

1 Department of Communication, Northwestern University, Frances Searle Building, 2240 Campus Drive, Room 2-133, Evanston, IL 60208, USA

2 Department of Sociology, University of Connecticut, Unit 1068, 344 Mansfield Rd., Storrs, CT 06269, USA

3 Department of Sociology, University of California, Berkeley, 410 Barrows Hall, Berkeley, CA 94720-1980, USA 
of abolishing the experience of the world itself, replaced with the effort to read about the world instead; and it makes the social universe more legible at the same time that it becomes more opaque. The duality also rests on the excess detritus from the silences, omissions, noise pollution, fragmented information, and incomplete character of the search for total knowledge. It harbors the inner tension of trying to think of anything and everything as classifiable and the seemingly endless proliferation of both objects of inquiry and the analytic categories needed to make sense of them.

There is also the clairvoyant character of the archival enterprise. By organizing the past, the archive imagines the future. It raises the fundamental question: what kinds of practices are needed to inform and analyze the dynamic relationships between the past and future? In this special issue, we learn about the archive as a forest in search of organizational principles that can serve as a corpus of sociological "proof." The articles examine how archival work is qualitative sociology, in that it resembles the dilemmas and processes that qualitative researchers confront when collecting and generating evidence and analyzing cases.

For instance, like ethnographic knowledge, historical knowledge is incomplete, filled with an abundance of detail. Historical researchers cannot capture the entire sea of undifferentiated dates, events, and places. Instead, they isolate bits and piece of the archive to make sense of sociological cases and to build sociological arguments. Historical researchers seek out the connections and the contrasts between different pieces of evidence. The archive also comes to resemble the ethnographic field site. It is not a static location waiting for researchers. Instead, archival work entails making sense of the resources that become available and assembling a specific collection related to the social issue, event, or problem. Historical researchers accumulate the details, and like ethnographers, they categorize observations, discard pieces of information that are unrelated to the topic at hand, narrow down their conceptual frameworks, and identify what remains essential versus what becomes excess or useless for the sociological cases.

Ethnographers sometimes behave like historians. They may participate in and observe the lives of their research subjects, but they also often trust indirect testimonies of the experiences they are interested in recording. They cannot always directly observe events or situations; instead, they learn about them by talking to witnesses and informants and seeking out variations in perspectives. Building up the ethnographic field notes and interview transcripts then leads to exclusion by convenience or efficiency. In fact, ethnographers may never become aware of the missing pieces, perspectives, or variations they are overlooking or avoiding.

Silencing may not be strategic, but it is commonplace. Historians are keenly aware on how archives often silence the marginal, the poor, and the illiterate populations, in large part because archives do not hold the primary sources needed to be more inclusive. Locating the subjugated knowledge requires a different kind of research endeavor. Historians may have to seek out alternative avenues and sources or face the possibility that no records remain - not everyone can find a Menocchio, as in Carlo Ginzburg's (1980) The Cheese and The Worms. For ethnographers, the problem is the opposite. They tend to focus on the excluded. One of the main reasons for this focus is that the marginal are more accessible. It is difficult for ethnographers to get access to corporate board meetings, attend private events among the wealthiest, interview state political figures, and participate in the worlds of those who hold the power to coordinate and control information and resources.

Both of these qualitative approaches - ethnography and archival work - must still translate evidence into narrative, and to a certain extent, that requires letting go of some of the hard-won documentation. Sociologists are not typically writing to exhibit some extraordinary piece of 
data. Rather, they are looking to justify the research excursion on disciplinary terms, through a mix of documentation and explanation. Following the heroic moment of data accumulation comes the ascetic and sober exercise of distancing oneself from the data, analyzing it, and communicating the meaning to others.

The advantage of ethnography might be precisely its incomplete and limited character (Candea 2010), an admission of the impossible closure in describing otherness. Ethnographers do not record the totality of social life in particular places. They organize an observed reality that is multiform, complex, and contradictory, according to and limited by the questions they want to answer. For this reason, ethnographers do not interpret documents as the definitive proof of something. Documents serve as an inscription or maybe an end point of a collective process attuned to organizational needs and interests and in tension with formal protocols.

The papers in this special issue examine these contradictory tendencies that link together archival work as qualitative sociology. They show that despite the perception of archives as durable halls of storage and objective information, evidence and analysis also fit into a dynamic cultural web that demands multiple sides of interpretation. One side demonstrates fragmentation in archival coordination that opens up a useful understanding of the context of archival production. The archival production reveals the dynamic relationships between power and ambiguity, creating spaces of both information and omission. On the other side is the disciplinary structuring of sociological research, the career of the historical sociologist in which fragmentation and omission work toward a different purpose: to create sociological interpretations of historical documents and the classification of sociological themes.

The papers explore four modes of inquiry through which archival work is qualitative sociology: the process of assembling the archive; the process of gaining access to the archive; the process of building an audience based on research in the archive; and the process of creating new worlds of possible political, economic, and social agencies out of the archival infrastructures and documents.

The first mode of inquiry refers to the work of assembling the archives out of disjointed conditions. Authors look at the deeply contextualized culture and politics of putting together our historical record. There is contestation over what actors think any given archives are for, what they understand as the series of historical events that have shaped archival and evidentiary formation and transformation, and for what purposes and for which actors the archives and the materials they hold were made and sustained. Inquiries into archival creation and transformation demonstrate key processes of problem-solving, knowledge collaboration, and contestation.

The archive coordinates and stores information, but it also fragments and disperses it to the point of manufacturing blind spots for those who want to conduct research and assemble coherent sociological narratives. This is especially the case in the conflict archive, in which information is actively being erased. Aliza Luft provides such an account of the relationship between the archives of the Centre de Documentation Juive Contemporaine in Paris, the YIVO Institute for Jewish Research in New York, and the Yad Vashem International Institute for Holocaust Research in Jerusalem. In this account, Luft gets beyond post hoc representations and inventions of the Holocaust. She raises important questions about what constitutes a Holocaust archive and the classifications of "Jewishness."

Luft investigates the multilayered unsettling of the historical ties between knowledge and place, as the conflict archive leads to the reimagining of its purpose: as storehouse of information and knowledge, as cultural production, and as genealogy. In this regard, her account reveals how competing voices and interests are reconstructed in the face of shared 
travesty. Inquiring into the unsettled times does not only locate the traumatic context of archival origins, it also demonstrates the eventual break with the archive's initial strategic purposes. Luft explains what is at stake in resolving this uncertainty and the reassembling of information in new contexts. How we engage with information and materials can be become both a memorial of the past and a guide to shaping our collective memories into the future.

Chandra Mukerji's account of archival coordination in seventeenth-century France is about using archival construction to invent national precedent for the purpose of logistical coordination and state formation, to cut down on corruption. The archive leaves behind traces of the primary goals and the overlooked work of a particular historical time. But her article also captures the story of engaging with historical materials in the present and trying to think through those very tensions of temporality. Archival materials are not just objects, not just voices, not just isolated decisions and points of information; they are symbolic classifications and materials assembled in the past and the present with differing purposes and goals in mind.

The qualitative sociologist is fundamentally interested in the archive's context of assembling because it is in this context where we can situate meaning, intent, and decisions. It is where we can underscore the categories of practice and not just the categories of analysis. We see this dynamic at play in Clayton Childress, Abigail Calonga, and Erik Schneiderhan's work in the Mandela archive. There is an unlocking of the fragmented and contested elements of the story, not just of a controversial historical period, but also of the inner stresses on an icon who was a complex person and much more than a symbolic figure. Reconstructing the history of Mandela's writing practices is about contextualizing a historical moment, presenting a person struggling to shape his own story with his own uncertainties about his role in writing the narrative of Apartheid. Mandela was aware that he was, in some ways, writing the guide to the future of South Africa.

Researchers' ability to capture the multi-dimensional moment in context shapes their ability to craft sociological questions. The origin story of the archival collection allows researchers a lens into what is being put together and potentially what is falling apart. And maybe most importantly, the conflict archive concerned with defining and redefining the Holocaust or Apartheid is unlike the Foucauldian archeological scheme. It creates a space for the subjugated to play a role in defining the context and setting up the questions for the future. This kind of perspective affects how we think of research and the distinct episteme of archival coordination. The conflict archive, by bringing the subjugated into the fold as central to the writing of history, presents new ways to conceptualize archival power that is distinct from the state-level information of censuses and authority. Power is not about demolishing the weak, rather the conflict molds into another form of authority and classification that drives future understandings and future ways of doing research.

History is not only in the past - it is being made as researchers look for stories to tell, both constructing new stories and challenging the stories that already exist. This repositioning of time and context is tied to the second related mode of inquiry about archival work as qualitative sociology. The archive is presented as separated from its historical origins. Instead of serving as the context of production, the archive presents a new context of discovery in which creating access to information is central. In this point, the insight is not about an origin story of the archive, but rather, the origin story of the researcher's interface in the archive. Like other forms of qualitative sociology, archival work is a complex negotiation and working out of what kinds of sociological questions we are interested in asking and what kinds of data are then made available that either challenge prior interpretations or help to assemble some narrative coherence. 
One of the clear constraints is fragmentation into different information storehouses, as Luft demonstrates. Another is what Childress, Calonga, and Schneiderhan and Damon Mayrl and Nicholas Wilson find: there are hidden pathways to information in particular archives. They show that librarians and archivists are not just dispensers of materials. They also make choices about what to show which researchers. Like ethnographers building rapport with their subjects, historical sociologists need to cultivate trust to facilitate the collection of data.

But even then, just like ethnographic access to subjects in field sites, some archives are easier for historical sociologists to navigate than others, more open to researchers than others. This system of knowledge can serve as a path of resistance and maybe a path of least resistance, which further influences how archival work is qualitative sociology. It is similar to how ethnographers iteratively enter into a community or a group to become a participant. What if ethnographers cannot get access? Some subjects are more forthcoming than others. What are subjects omitting or censoring in their presentation of self? What kinds of information about their families, organizations, or neighborhoods are they keeping from the ethnographer?

Ethnographers might be able to just ask different subjects to fulfill the purpose of the inquiry. Archival researchers face a different set of constraints. The specific archive itself may not offer the full portrait, such that historical sociologists proceed to reconstruct a history. That is, to unlock the variations on a theme, they may have to find complementary archives and think through the connections and contrasts between different kinds of data assembled in different kinds of archives. Building on Diane Vaughan's $(1996,2004)$ seminal historical ethnography of NASA's Challenger launch, Armando Lara-Millán, Brian Sargent, and Sunmin Kim juxtapose the explanation researchers bring to the archives with the explanations that actors in the archives tell us. It is precisely the reflection on this comparison that leads to sociological theories gleaned from the incomplete archive.

Another way of framing this question is: How do archival researchers make sure they have identified the pattern and not the negative case? How do they find the relationship between those dimensions of building their sociological arguments? Like good qualitative research, archival work involves creative ways to push up against the established narrative in search of variations and negative cases, to exploit the ambiguity for explanatory and interpretive purposes, so that they can better articulate the case itself.

The third related piece of archival work as qualitative sociology is the disciplinary side of the equation, which comes with a host of epistemic assumptions and competencies into selection criteria. Here, we have a different set of omissions related to the context of discovery and the form of sociological questioning. Much has been written in qualitative sociology about getting the facts right. There are classic accounts raising concerns about ethnographic validity, including those written by luminaries like Howard Becker and William H. Whyte. It is an ageold debate in ethnography: how to make sure you are not just capturing what people say, but also what people do.

But this issue of validity is not only a matter of getting the facts right or wrong. Doing due diligence to the facts is important. But facts are not enough in sociology. There is a professionalization of the sociologist in the archive, and this is as much about epistemic factors. Ethnographers are not journalists. They have disciplinary affiliations, in this case, as sociologists. The historical sociologist is not a historian, and likewise, the historical ethnographer is not a comparative historical sociologist. The question is not should "we" do what "they" do, but rather, it raises the question of what is similar and different about how researchers take for granted what they know and what they want to do in the archive. 
The issue of what you leave out is in part about archival gatekeeping, which is a form of power toward censoring information and access. But another part of narrowing down the sociological endeavor is the logic of inquiry. Sociologists do certain kinds of empirical work and ask certain kinds of questions to make their interpretations and theories fit with the available data and its variations. We can see this archival work as qualitative sociology in Childress, Calonga, and Schneiderhan's and Mayrl and Wilson's analyses of the careers and professionalization pathways of the sociologists doing archival research. The historical sociologist must navigate distinct professional stages and dynamics in order to "become historical sociologists."

Lara-Millán, Sargent, and Kim also take on this question, not in focusing on the search for data, but in locating the connections between data and analysis. Starting from the point that archives are fragmented and impartial, they ask, how do historical sociologists produce theories from archives that others find externally relevant? The key for them is linking the confusion that actors in the archive experience to theories of the emergence of entities, actors, and other agents. Using insights from how ethnographers generate theory, they offer a rubric for what they view as compelling kinds of archival evidence that can inform sociological theorizing.

Archives produce routines and practices that lead to researcher professionalization and gatekeeping of evidence. But there is also a fourth mode of inquiry into archival work as qualitative sociology. In some cases, archival work is agentic, creating the social and political possibilities to remake the world anew. As archival work organizes and builds the universe of classifications, this work between analysis and documents can produce the very political agencies and practices that can be applied to populations that we then come to take for granted. The archive is a process of miniaturization. It reduces the world into files and gives life to certain categories of people and certain ways of measuring and controlling them. Documentation creates ways for people to think about themselves, their relations, their modes and categories of belonging, and how to apply those categories toward distinct ends.

We can see this process playing out in the conflict archives, depicted by Luft as competing versions of what it is to be Jewish. Yet this perspective takes its fullest form in Mukerji's paper. An archive can help actors build massive infrastructures that expand their own power. Mukerji shows how the building of the archives resulted in the extension of authority against the patrimonial and regal ways of governing in France. The archive had its own agency, giving rise to new types of information and measurement as the logistical character of power. Thinking of documents as agents allows us to see how the archives become evidentiary bases for political decisions. This point is further illustrated in Skarpelis's discussion of the different classificatory schemas of two ethnoracial Empires, Japan and Germany. The latter had a multiplicity of political nuances that distinguished it from the blanket characterizations of power in the former. In both cases, however, the archive served as the basis for future political actions concerning those populations.

In a recently published book, Katherine Verdery (2018) underscores the productive character of classifications, by delving into her own file created by the Romanian Secret Services and how her life was affected differently according to whether she was characterized as a spy, a CIA Agent, a Hungarian agitator, or a fellow traveler to dissidents. Each of these classifications had differential consequences for her own life while doing fieldwork in Romania. Anna Skarpelis's paper follows this thread. Using multiple examples from her own research and from scholarly literature in multiple disciplines, her paper attempts to theorize this dialectic exercise between life and file by adding Ian Hacking's (Hacking 1995) looping effect to it, 
wherein the meaning of a human science classification affects the behavior of those who fall under that classification.

Much like with other infrastructural objects, the agentic quality of archives presents a powerful window to the invisible work of assembling and disassembling. The archive is a world of coordination, but as the papers in this special issue demonstrate, it also harbors a world of knowledge disputes and contestations. The contradictions of the archive are evident across the board. As Everett Hughes (1970) once said, "Things could have been otherwise." Through archives we get to know how certainty and uncertainty are fragile partners. The historical record - the constant assembling and disassembling of Borges's Total Library—is contingent, opposed to teleology, and opening up new paths for sociological analysis and social, economic, and political action. To this end, these papers introduce archival work as qualitative sociology.

\section{References}

Candea, Matei. 2010. Corsican fragments: Difference, knowledge and fieldwork. Bloomington: Indiana University Press.

Ginzburg, Carlo. 1980. The cheese and the worms: The cosmos of a sixteenth century miller. Baltimore: John Hopkins University Press.

Hacking, Ian. 1995. The looping effects of human kinds. In Symposia of the Fyssen Foundation. Causal cognition: A multidisciplinary debate, eds. D. Sperber, D. Premack, and A.J. Premack, 351-394. Oxford: Oxford University Press.

Hughes, Everett. 1970. Mistakes at work. In his The Sociological Eye. Chicago: Aldine.

Vaughan, Diane. 1996. The challenger launch decision: Risky technology, culture, and deviance at NASA. Chicago: University of Chicago Press.

Vaughan, Diane. 2004. Theorizing disaster: Analogy, historical ethnography, and the challenger accident. Ethnography 5 (3): 315-347.

Verdery, Katherine. 2018. My life as a spy: Investigations in a secret police file. Durham: Duke University Press.

Publisher's Note Springer Nature remains neutral with regard to jurisdictional claims in published maps and institutional affiliations. 